\title{
Double-Proton-Transfer Processes in Dithiooxamide: UV-Induced Dithione $\rightarrow$ Dithiol Reaction and Ground-State Dithiol $\rightarrow$ Dithione Tunneling
}

\author{
Leszek Lapinski, ${ }^{\dagger, \ddagger}$ Hanna Rostkowska, ${ }^{\dagger}$ Artem Khvorostov, ${ }^{\dagger}$ Miijgan Yaman, \\ Rui Fausto, \\ Institute of Physics, Polish Academy of Sciences, Al. Lotnikow 32/46, 02-668 Warsaw, Poland, and Department \\ of Chemistry, University of Coimbra, P-3004-535 Coimbra, Portugal
}

Received: February 18, 2004; In Final Form: April 20, 2004

\begin{abstract}
Dithiooxamide [rubeanic acid, $\left.\mathrm{NH}_{2} \mathrm{C}(=\mathrm{S}) \mathrm{C}(=\mathrm{S}) \mathrm{NH}_{2}\right)$ ] monomers were studied by FTIR spectroscopy combined with the low-temperature matrix-isolation technique. The most stable dithione-diamino tautomer of the compound was exclusively observed in argon matrixes immediately after deposition. Upon UV ( $\lambda>345$ $\mathrm{nm}$ ) irradiation the dithione-diamino form transformed, by a double-proton transfer, into the dithiol-diimino tautomer. Theoretically supported analysis of the infrared spectrum emerging upon UV irradiation allowed identification of one of the conformers of the dithiol-diimino tautomer as the dominating photoproduct. Smaller quantities of other conformers of the dithiol-diimino tautomer were also found to be photogenerated. For the UV-irradiated matrix kept subsequently at $10 \mathrm{~K}$ and in darkness, a dithiol-diimino $\rightarrow$ dithionediamino tautomerization leading to partial recovery of the initial form of the compound was observed. The only possible mechanism of this ground-state transformation at cryogenic temperature is synchronous doubleproton tunneling. The experimentally obtained time constant of this process was $18 \mathrm{~h}$.
\end{abstract}

\section{Introduction}

Phototautomeric reactions converting the thione-amino forms of simple thioamides, such as thiourea ${ }^{1}$ and thioacetamide, ${ }^{2}$ into the corresponding thiol-imino isomers were recently observed for compounds isolated in low-temperature inert gas matrixes. Intramolecular thione $\rightarrow$ thiol phototransformations were also observed for some heterocyclic compounds: 2(1H)-pyridinethione, ${ }^{3} 2(1 H)$-quinolinethione, ${ }^{4} 3(2 H)$-pyridazinethione, and $4(3 H)$ pyrimidinethione. ${ }^{5}$ In all cases, a proton was transferred from the NH group to the sulfur atom of the thiocarbonyl group placed in the $\alpha$ position with respect to the nitrogen atom (Scheme 1). So far, UV-induced double-proton-transfer processes have been reported for only two molecules: 2,4-dithiouracil ${ }^{6}$ and 2,6dithiopurine. ${ }^{7}$ Notably, in the latter case the dominating photoprocess corresponded to proton transfer from the $\beta$ position (Scheme 2).

The molecule of dithiooxamide (DTO) is built of two thioamide units connected by a single $\mathrm{C}-\mathrm{C}$ bond (Chart 1 ). It was demonstrated ${ }^{8}$ that in the crystalline state the compound adopts the dithione-diamino tautomeric form (shown in Chart 1). On considering this structure of DTO, it is easy to notice that, in principle, proton transfers are possible from amino groups to the thiocarbonyl groups placed at $\alpha$ and $\beta$ positions.

Recently, an unusual occurrence of thiol $\rightarrow$ thione groundstate proton tunneling through a very high energy barrier (ca. $105 \mathrm{~kJ} \mathrm{~mol}^{-1}$ ) was observed for matrix-isolated thiourea ${ }^{1}$ at 10 $\mathrm{K}$. During this process the photoproduced thiol form of thiourea was transformed back into the initial thione form of the compound. The time constant of this conversion was $52 \mathrm{~h}$. As far as we know, this observation of proton tunneling through

* To whom correspondence should be addressed. E-mail: mjnowak@ ifpan.edu.pl.

Polish Academy of Sciences.

$\doteqdot$ University of Coimbra.
SCHEME 1: UV-Induced Proton Transfer to the Sulfur Atom in the $\alpha$ Position $^{1-5}$

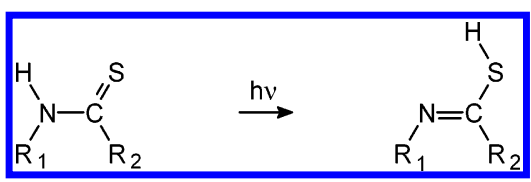

SCHEME 2: UV-Induced Proton Transfer from the $\mathrm{N}-\mathrm{H}$ Group to the Sulfur Atom in the $\beta$ Position $^{a, 7}$

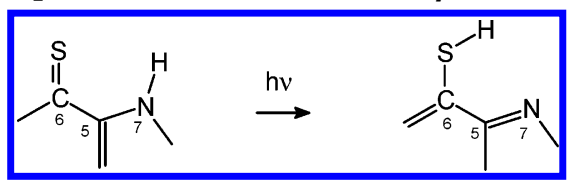

${ }^{a}$ The numbers refer to the standard atom numbering in purines.

\section{CHART 1: Dithione-Diamino Tautomer I of} Dithiooxamide $^{a}$

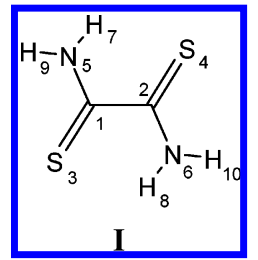

${ }^{a}$ According to MP2/6-311++G(2d,p) calculations, this form is planar with $C_{2 h}$ symmetry.

such a high barrier was unprecedented. Very recently, an analogous (selenol $\rightarrow$ selenone) proton-tunneling process has been reported for selenourea. ${ }^{9}$ In that case, the barrier for the ground-state selenol $\rightarrow$ selenone tautomerization was somewhat lower (ca. $95 \mathrm{~kJ} \mathrm{~mol}^{-1}$ ) and the tunneling process was faster (time constant $16 \mathrm{~h}$ ). As far as isolated, monomeric molecules are concerned, no other example of proton tunneling through barriers of comparable height has previously been reported. 
TABLE 1: Symmetry Coordinates Used in the Normal-Mode Analysis for the Dithione-Diamino Tautomer I of Dithiooxamide ${ }^{a}$

\begin{tabular}{|c|c|c|}
\hline definition & symmetry & symbol \\
\hline $\begin{array}{l}S_{1}=\left(2^{-1 / 2}\right)\left(r_{1,3}-r_{2,4}\right) \\
S_{2}=\left(2^{-1 / 2}\right)\left(r_{1,5}-r_{2,6}\right) \\
S_{3}=\left(2^{-1 / 2}\right)\left(r_{5,9}-r_{6,10}\right) \\
S_{4}=\left(2^{-1 / 2}\right)\left(r_{5,7}-r_{6,8}\right) \\
S_{5}=(1 / 2)\left(\beta_{4,1,2}-\beta_{4,6,2}-\beta_{3,2,1}+\beta_{3,5,1}\right) \\
S_{6}=(1 / 2)\left(\beta_{6,1,2}-\beta_{6,4,2}-\beta_{5,2,1}+\beta_{5,3,1}\right) \\
S_{7}=\left(12^{-1 / 2}\right)\left(2 \beta_{7,9,5}-\beta_{7,1,5}-\beta_{9,1,5}-2 \beta_{8,10,6}+\beta_{8,2,6}+\beta_{10,2,6}\right) \\
S_{8}=(1 / 2)\left(\beta_{9,1,5}-\beta_{7,1,5}-\beta_{10,2,6}+\beta_{8,2,6}\right) \\
S_{9}=\left(8^{-1 / 2}\right)\left(\tau_{9,5,1,2}+\tau_{9,5,1,3}+\tau_{7,5,1,2}+\tau_{7,5,1,3}+\tau_{10,6,2,1}+\tau_{10,6,2,4}+\tau_{8,6,2,1}+\tau_{8,6,2,4}\right) \\
S_{10}=\left(2^{-1 / 2}\right)\left(\gamma_{1,7,5,9}+\gamma_{2,8,6,10}\right) \\
S_{11}=\left(2^{-1 / 2}\right)\left(\gamma_{2,5,1,3}+\gamma_{1,6,2,4}\right) \\
S_{12}=(1 / 2)\left(\tau_{4,2,1,3}+\tau_{4,2,1,5}+\tau_{6,2,1,3}+\tau_{6,2,1,5}\right)\end{array}$ & $\begin{array}{l}\mathrm{B}_{\mathrm{u}} \\
\mathrm{B}_{\mathrm{u}} \\
\mathrm{B}_{\mathrm{u}} \\
\mathrm{B}_{\mathrm{u}} \\
\mathrm{B}_{\mathrm{u}} \\
\mathrm{B}_{\mathrm{u}} \\
\mathrm{B}_{\mathrm{u}} \\
\mathrm{B}_{\mathrm{u}} \\
\mathrm{A}_{\mathrm{u}} \\
\mathrm{A}_{\mathrm{u}} \\
\mathrm{A}_{\mathrm{u}} \\
\mathrm{A}_{\mathrm{u}}\end{array}$ & $\begin{array}{l}\nu(\mathrm{C}=\mathrm{S}) \\
\nu(\mathrm{CN}) \\
\nu_{1}(\mathrm{NH}) \\
v_{2}(\mathrm{NH}) \\
\beta(\mathrm{C}=\mathrm{S}) \\
\beta(\mathrm{CN}) \\
\text { scis } \mathrm{NH}_{2} \\
\text { rock } \mathrm{NH}_{2} \\
\text { twist } \mathrm{NH}_{2} \\
\text { wag } \mathrm{NH}_{2} \\
\text { wag thioamide } \\
\text { twist } \mathrm{C}-\mathrm{C}\end{array}$ \\
\hline
\end{tabular}

${ }^{a}$ Atom numbering as in Chart 1 . Symmetry coordinates belonging to the $\mathrm{A}_{\mathrm{g}}$ and $\mathrm{B}_{\mathrm{g}}$ representations are not included. Normal modes with $\mathrm{A}_{\mathrm{g}}$ or $\mathrm{B}_{\mathrm{g}}$ symmetry are not active in IR. $r_{i, j}$ is the distance between atoms $\mathrm{A}_{i}$ and $\mathrm{A}_{j} . \beta_{i, j, k}$ is the angle between vectors $\mathrm{A}_{k} \mathrm{~A}_{i}$ and $\mathrm{A}_{k} \mathrm{~A}_{j} . \tau_{i, j, k, l}$ is the dihedral angle between the plane defined by the $\mathrm{A}_{i}, \mathrm{~A}_{j}$, and $\mathrm{A}_{k}$ atoms and the plane defined by the $\mathrm{A}_{j}, \mathrm{~A}_{k}$, and $\mathrm{A}_{l}$ atoms. $\gamma_{i, j, k, l}$ is the angle between the vector $\mathrm{A}_{k} \mathrm{~A}_{i}$ and the plane defined by atoms $\mathrm{A}_{j}, \mathrm{~A}_{k}$, and $\mathrm{A}_{l}$.

In the present paper, the UV-induced dithione $\rightarrow$ dithiol double-proton-transfer reaction in matrix-isolated DTO is reported. Observation of the ground-state dithiol $\rightarrow$ dithione double-proton tunneling, leading to recovery of the initial dithione form, is also accounted for. We are not aware of any reports on similar cases of synchronous double-proton tunneling.

\section{Experimental Section}

The sample of dithiooxamide $(98 \%)$ was obtained from Aldrich and used without further purification. To deposit the matrix, crystalline DTO was electrically heated in a miniature glass oven placed in the vacuum chamber of a continuous flow helium cryostat. The vapors of the compound were frozen together with a large excess of an inert gas on a CsI window cooled to $10 \mathrm{~K}$. The argon matrix gas was of spectral purity, as supplied by Linde AG. Infrared spectra were recorded in the range $4000-200 \mathrm{~cm}^{-1}$, at $0.5 \mathrm{~cm}^{-1}$ resolution, using a Thermo Nicolet Nexus 670 FTIR spectrometer equipped with $\mathrm{KBr}$ and "solid substrate" beam splitters and DTGS detectors. Integral intensities of the IR absorption bands were measured by numerical integration.

Matrixes were irradiated with light from the HBO200 highpressure mercury lamp fitted with a water filter and a cutoff filter transmitting light with $\lambda>345 \mathrm{~nm}$. The typical irradiation time was $1 \mathrm{~h}$.

\section{Computational Details}

The molecular geometries of isomers of DTO were optimized at the density functional theory (DFT(B3LYP)) level, with Becke's three-parameter exchange functional and gradientcorrected functional of Lee, Yang, and Parr. ${ }^{10-12}$ The standard $6-31++\mathrm{G}(\mathrm{d}, \mathrm{p})$ basis set $^{13}$ was used in these calculations. Harmonic vibrational frequencies and IR intensities were then calculated at the optimized geometries. To correct for systematic shortcomings of the applied methodology (mainly for anharmonicity), the predicted vibrational wavenumbers were scaled down with a single factor of 0.98 . The standard potential energy distribution (PED) analysis ${ }^{14}$ of the calculated normal modes was performed. The symmetry coordinate system used in this analysis is presented in Tables 1 and 3 (see also Table S1 in the Supporting Information).

The barrier for concerted double-proton transfer in the electronic ground state was calculated using the minimum energy path approach. At each of the points intermediate between the dithiol-diimino and dithione-diamino tautomeric forms, all geometry parameters (except for the driving coordi- nate) were optimized, with conservation of the $C_{2 h}$ symmetry, using the MP2 method ${ }^{15,16}$ and the $6-311++\mathrm{G}(2 \mathrm{~d}, \mathrm{p})$ basis set. The GAUSSIAN 98 program $^{17}$ was used in all the cases.

\section{Results and Discussion}

Dithiooxamide Monomers. Thione-amino tautomeric forms of simple thioamides (thioformamide, thioacetamide, thiourea) are more stable than thiol-imino forms. Theoretical calculations predict for these compounds energy differences between the thione-amino and thiol-imino tautomers as large as 39-55 $\mathrm{kJ} \mathrm{mol}^{-1} \cdot 1,2,18$ Such a significant energy difference prohibits thermal population of thioamide isomers other than the most stable tautomer. Indeed, only the thione-amino forms of simple thioamides were experimentally observed until very recently, when photochemical generation of thiol-imino tautomers was reported. ${ }^{1,2}$

Tautomerism of DTO follows the general pattern known from previous studies of the simplest thioamides. The dithionediamino planar structure I, with overall symmetry $C_{2 h}$ (Chart 1 ), is theoretically predicted to be the most stable form of the compound. This isomer is stabilized by four intramolecular, hydrogen-bond-like interactions. Moreover, in structure I repulsion between the lone electron pairs of the sulfur atoms (as well as repulsion between the hydrogen atoms) is minimal. No further minima could be located on the potential energy surface of the dithione-diamino tautomer of DTO. In particular, the structure with the sulfur atoms on the same side of the $\mathrm{C}-\mathrm{C}$ bond was found to be a saddle point lying $77 \mathrm{~kJ} \mathrm{~mol}^{-1}$ (DFT(B3LYP)/ $6-31++\mathrm{G}(\mathrm{d}, \mathrm{p}))$ above the stable conformer $\mathbf{I}$, whereas all structures exhibiting a nonplanar arrangement around the $\mathrm{C}-\mathrm{C}$ bond were found to converge upon optimization to the most stable, planar form $\mathbf{I}$.

Other tautomers of DTO are much higher in energy. The second most stable form of the compound, conformer II (Chart 2) of the dithiol-diimino tautomer, was predicted to be energetically higher by $85.3 \mathrm{~kJ} \mathrm{~mol}^{-1}$, with respect to isomer I. The relative energy of these isomers was calculated at the MP2/6-311++G(2d,p) level and corrected for zero-point vibrational energy using the normal-mode frequencies computed at the DFT(B3LYP)/6-31++G(d,p) level. The experimental infrared spectrum of DTO isolated in an Ar matrix is presented in Figure 1. This spectrum is compared with the results of a theoretical simulation carried out at the DFT(B3LYP)/6$31++G(d, p)$ level for form $\mathbf{I}$. The symmetry of the molecule reduces the number of infrared active modes to 12 . The agreement between the experimental and theoretical spectra is 
TABLE 2: Experimental Wavenumbers $\left(\tilde{v} / \mathrm{cm}^{-1}\right)$ and Relative Integral Intensities $(I)$ of the Absorption Bands of Matrix-Isolated Dithiooxamide, Compared with the Wavenumbers $\left(\tilde{v} / \mathrm{cm}^{-1}\right)$, Absolute Intensities $\left[A^{\text {th }} /\left(\mathrm{km} \mathrm{mol}^{-1}\right)\right]$, and Potential Energy Distribution (PED/\%) Theoretically Calculated for the Dithione-Diamino Form I of the Compound

\begin{tabular}{|c|c|c|c|c|}
\hline \multicolumn{2}{|c|}{ experimental, Ar matrix } & \multicolumn{3}{|c|}{ calculated, DFT(B3LYP)/6-31++G(d,p) } \\
\hline$\tilde{\nu}^{a}$ & $I$ & $\tilde{v}^{b}$ & $A^{\text {th }}$ & $\mathrm{PED}^{c}$ \\
\hline $3494 / 3491$ & 294 & 3619 & 209 & $v_{1}(\mathrm{NH})(87), v_{2}(\mathrm{NH})(14)$ \\
\hline $3277 / 3273$ & 329 & 3414 & 215 & $v_{2}(\mathrm{NH})(86), v_{1}(\mathrm{NH})$ \\
\hline $1547 / 1537$ & 428 & 1566 & 490 & scis $\mathrm{NH}_{2}(80), v(\mathrm{CN})(19)$ \\
\hline 1394/1392 & 310 & 1388 & 301 & $v(\mathrm{CN})(72)$, scis $\mathrm{NH}_{2}(19)$ \\
\hline 1381 & 38 & & & \\
\hline 1344 & 31 & & & \\
\hline 1276 & 4 & & & \\
\hline 1266 & 7 & & & \\
\hline $1258 / 1256$ & 25 & & & \\
\hline 1237 & 5 & & & \\
\hline 1224 & 52 & 1207 & 134 & $\operatorname{rock} \mathrm{NH}_{2}(76), \beta(\mathrm{CN})(11)$ \\
\hline 1154 & 4 & & & \\
\hline 1150 & 2 & & & \\
\hline 1119/1116/1113 & 87 & & & \\
\hline $1048 / 1043$ & 74 & & & \\
\hline 891 & 5 & & & \\
\hline $863 / 860 / 856 / 852$ & 61 & 847 & 60 & $v(\mathrm{C}=\mathrm{S})(77)$, rock $\mathrm{NH}_{2}(17)$ \\
\hline $640 / 639$ & 12 & 647 & 17 & twist $\mathrm{NH}_{2}(94)$ \\
\hline $524 / 523$ & 219 & 505 & 278 & wag $\mathrm{NH}_{2}$ (86), wag thioamide (14) \\
\hline 448 & 1 & 449 & 1 & $\beta(\mathrm{CN})(67), \beta(\mathrm{C}=\mathrm{S})(19)$ \\
\hline $389 / 386$ & 33 & 382 & 50 & wag thioamide (86), wag $\mathrm{NH}_{2}(11)$ \\
\hline $283 / 282$ & 27 & 270 & 26 & $\beta(\mathrm{C}=\mathrm{S})(78), \beta(\mathrm{CN})(21)$ \\
\hline & & 48 & 7 & twist $\mathrm{C}-\mathrm{C}(102)$ \\
\hline
\end{tabular}

${ }^{a}$ Wavenumbers of the strongest bands are italic. ${ }^{b}$ Theoretical wavenumbers were scaled by a factor of $0.98 .{ }^{c}$ PEDs lower than $10 \%$ are not included. Symmetry coordinates used in the normal-mode analysis are given in Table 1.

TABLE 3: Symmetry Coordinates Used in the Normal-Mode Analysis for Conformer II of the Dithiol-Diimino Tautomer of Dithiooxamide ${ }^{a}$

\begin{tabular}{lcl}
\hline \multicolumn{1}{c}{ definition } & symmetry & \multicolumn{1}{c}{ symbol } \\
\hline$S_{1}=r_{1,3}-r_{2,4}$ & $\mathrm{~B}_{\mathrm{u}}$ & $\nu(\mathrm{CS})$ \\
$S_{2}=r_{1,5}-r_{2,6}$ & $\mathrm{~B}_{\mathrm{u}}$ & $v(\mathrm{C}=\mathrm{N})$ \\
$S_{3}=r_{5,9}-r_{6,10}$ & $\mathrm{~B}_{\mathrm{u}}$ & $\nu(\mathrm{NH})$ \\
$S_{4}=r_{3,8}-r_{4,7}$ & $\mathrm{~B}_{\mathrm{u}}$ & $\nu(\mathrm{SH})$ \\
$S_{5}=\beta_{4,1,2}-\beta_{4,6,2}-\beta_{3,2,1}+\beta_{3,5,1}$ & $\mathrm{~B}_{\mathrm{u}}$ & $\beta(\mathrm{CS})$ \\
$S_{6}=\beta_{6,1,2}-\beta_{6,4,2}-\beta_{5,2,1}+\beta_{5,3,1}$ & $\mathrm{~B}_{\mathrm{u}}$ & $\beta(\mathrm{C}=\mathrm{N})$ \\
$S_{7}=\beta_{10,2,6}-\beta_{9,1,5}$ & $\mathrm{~B}_{\mathrm{u}}$ & $\beta(\mathrm{NH})$ \\
$S_{8}=\beta_{8,1,3}-\beta_{7,2,4}$ & $\mathrm{~B}_{\mathrm{u}}$ & $\beta(\mathrm{SH})$ \\
$S_{9}=\tau_{9,5,1,2}+\tau_{9,5,1,3}+\tau_{10,6,2,1}+\tau_{10,6,2,4}$ & $\mathrm{~A}_{\mathrm{u}}$ & $\tau(\mathrm{NH})$ \\
$S_{10}=\tau_{8,3,1,2}+\tau_{8,3,1,5}+\tau_{7,4,2,1}+\tau_{7,4,2,6}$ & $\mathrm{~A}_{\mathrm{u}}$ & $\tau(\mathrm{SH})$ \\
$S_{11}=\gamma_{2,5,1,3}+\gamma_{1,6,2,4}$ & $\mathrm{~A}_{\mathrm{u}}$ & wag thioamide \\
$S_{12}=\tau_{4,2,1,3}+\tau_{4,2,1,5}+\tau_{6,2,1,3}+\tau_{6,2,1,5}$ & $\mathrm{~A}_{\mathrm{u}}$ & twist C-C
\end{tabular}

${ }^{a}$ Atom numbering as in Chart 2. Symmetry coordinates belonging to the $\mathrm{A}_{\mathrm{g}}$ and $\mathrm{B}_{\mathrm{g}}$ representations are not included. Normal modes with $\mathrm{A}_{\mathrm{g}}$ or $\mathrm{B}_{\mathrm{g}}$ symmetry are not active in IR. $r_{i, j}$ is the distance between atoms $\mathrm{A}_{i}$ and $\mathrm{A}_{j} . \beta_{i, j, k}$ is the angle between vectors $\mathrm{A}_{k} \mathrm{~A}_{i}$ and $\mathrm{A}_{k} \mathrm{~A}_{j} \cdot \tau_{i, j, k, l}$ is the dihedral angle between the plane defined by the $\mathrm{A}_{i}, \mathrm{~A}_{j}$, and $\mathrm{A}_{k}$ atoms and the plane defined by the $\mathrm{A}_{j}, \mathrm{~A}_{k}$, and $\mathrm{A}_{l}$ atoms. $\gamma_{i, j, k, l}$ is the angle between the vector $\mathrm{A}_{k} \mathrm{~A}_{i}$ and the plane defined by atoms $\mathrm{A}_{j}, \mathrm{~A}_{k}$, and $\mathrm{A}_{l}$.

CHART 2: Conformer II of the Dithiol-Diimino Tautomer of $\mathrm{DTO}^{a}$

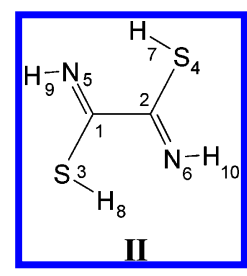

${ }^{a}$ According to MP2/6-311++G(2d,p) calculations, this form is planar with $C_{2 h}$ symmetry.

seen to be very good, allowing reliable assignment of the observed bands (Table 2; see also Table S2 in the Supporting Information). The small features at 1381, 1258, 1116, and 1048 $\mathrm{cm}^{-1}$, which have no counterparts in normal modes calculated in a harmonic approximation, can be caused by combinational modes or symmetry breaking due to matrix effects.

The strongest band in the spectrum is observed at $1547 \mathrm{~cm}^{-1}$ and is ascribed to the scissoring mode of the amino groups that is predicted at $1566 \mathrm{~cm}^{-1}$. The bands corresponding to the rocking, twisting, and wagging deformations of these groups were found at 1224,640 , and $524 \mathrm{~cm}^{-1}$, respectively (predicted values: 1207, 647, and $505 \mathrm{~cm}^{-1}$ ). The last frequency is considerably higher than that of the band due to the analogous vibration in thioacetamide, ${ }^{2}$ which is only $368 \mathrm{~cm}^{-1}$. The high frequency of the amino group wagging mode indicates a more pronounced interaction of $\mathrm{NH}$ hydrogen atoms with the sulfur lone electron pairs $\left(S_{1 p}\right)$ in DTO in comparison with the corresponding interaction in thioacetamide. There are two reasons for this: first, each of the amino groups in DTO has two $\mathrm{C}=\mathrm{S}$ neighbors, while in simple monothioamides there is only one $\mathrm{C}=\mathrm{S}$ neighbor; second, the $\mathrm{N}(5) \mathrm{H}(7) \cdots \mathrm{S}(4)_{l p}$ and $\mathrm{N}(6) \mathrm{H}(8) \cdots \mathrm{S}(3)_{\mathrm{lp}}$ interactions closing the five-membered rings in DTO (see Chart 1) are stronger than the $\mathrm{N}(6) \mathrm{H}(10) \cdots \mathrm{S}(4)_{\mathrm{lp}}$ and $\mathrm{N}(5) \mathrm{H}(9) \cdots \mathrm{S}(3)_{\text {lp }}$ interactions in the four-membered rings typical of simple thioamides. In the structure of form I optimized at the MP2/6-311++G(2d,p) level, the $\mathrm{H}(7) \cdots \mathrm{S}(4)$ distance is $2.399 \AA$, whereas the $\mathrm{H}(10) \cdots \mathrm{S}(4)$ distance is $2.811 \AA$.

The stronger $\mathrm{NH} \cdots \mathrm{S}_{\text {lp }}$ interaction observed in DTO is also revealed by the unusual coupling of the $\mathrm{NH}$ stretching vibrations. Instead of the typical "symmetric" and "antisymmetric" coupling of the individual NH oscillators of each amino group (which is usually observed for simple amides and thioamides), in DTO the NH stretching vibrations of the hydrogen atoms that are interacting with the sulfur lone electron pairs through fivemembered rings are coupled with each other and give rise to an infrared band observed at $3277 \mathrm{~cm}^{-1}$. The low frequency of this vibration indicates a relatively strong hydrogen-bond-like intramolecular interaction. In turn, the band observed at a higher frequency $\left(3494 \mathrm{~cm}^{-1}\right)$ is due to the $\mathrm{NH}$ stretching vibrations of the hydrogen atoms that interact with the sulfur lone electron 


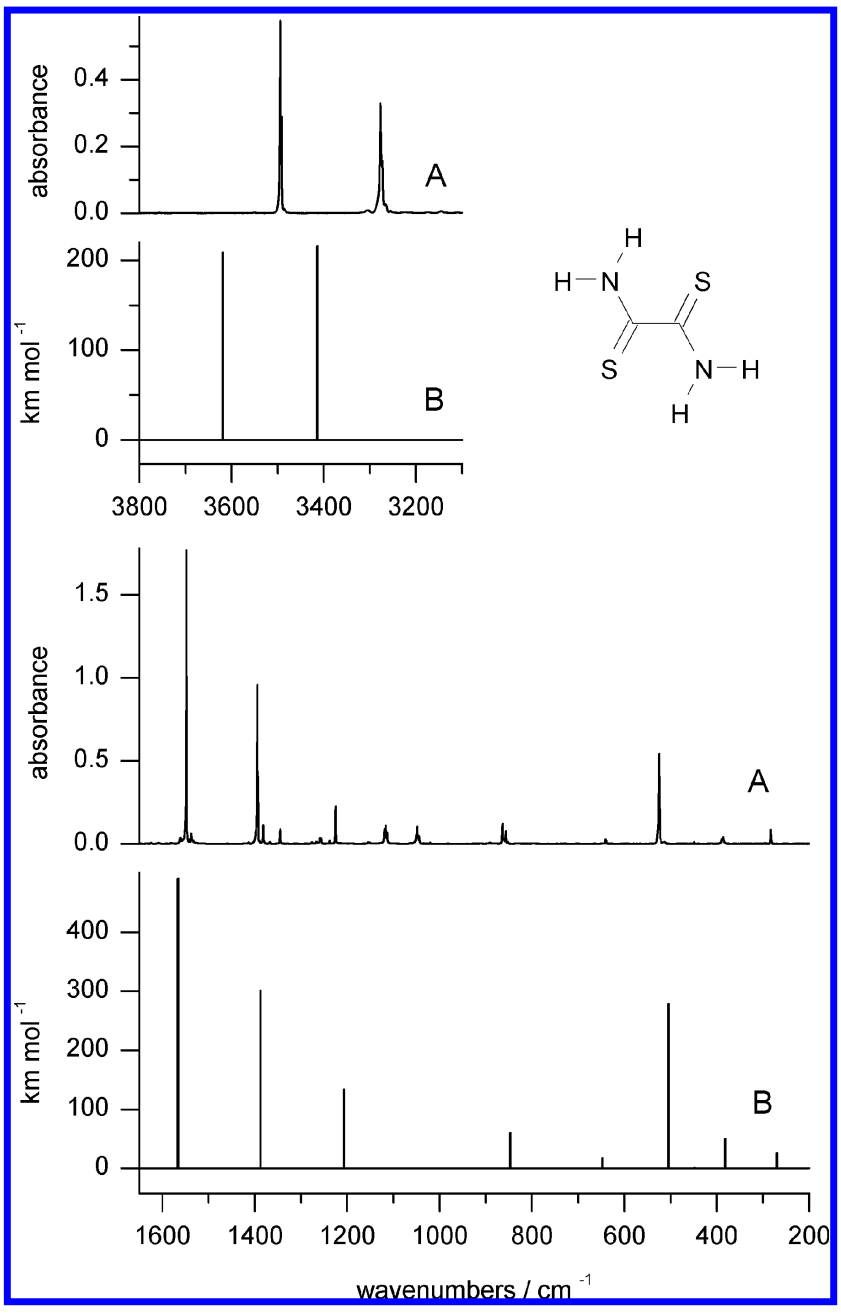

Figure 1. Infrared spectra of dithiooxamide: (A) isolated in an $\mathrm{Ar}$ matrix; (B) theoretically predicted at the DFT(B3LYP)/6-31++G(d,p) level for the dithione tautomeric form. Theoretical wavenumbers were scaled by 0.98 .

pairs through four-membered rings. This demonstrates that the $\mathrm{NH} \cdots \mathrm{S}_{\mathrm{lp}}$ interactions closing the four-membered ring are significantly weaker.

Double-Proton-Transfer Processes. After $1 \mathrm{~h}$ of $\mathrm{UV}(\lambda>$ $345 \mathrm{~nm}$ ) irradiation of the matrix, the initial IR spectrum disappeared almost completely, whereas new bands due to photoproduct(s) emerged (Figure 2). The characteristic features of the new spectrum are low intensities of the emerged bands, appearance of new bands in the $2610-2500 \mathrm{~cm}^{-1}$ region (typical frequency range of stretching $\mathrm{SH}$ vibrations, shown in Figure 3 ), and almost total disappearance of IR absorptions in the $3500-3250 \mathrm{~cm}^{-1}$ range (the $\mathrm{NH}$ stretching region). This suggests that UV irradiation promoted transformation of the dithione-diamino tautomer of DTO into the dithiol-diimino isomer(s). Note that the bands due to $\mathrm{NH}$ stretching vibrations of an imino group are always much less intense than the bands caused by NH stretching vibrations of an amino group. .,2,9 $^{2}$

An important characteristic of the spectrum of the main photoproduct(s) is the band due to the stretching vibrations of the $\mathrm{SH}$ groups $[v(\mathrm{SH})]$ found at $2521 \mathrm{~cm}^{-1}$ (Figure 3 ). The frequency of this band is lower and its intensity is higher than usually found for other matrix-isolated thiol molecules. For example, the bands due to $\mathrm{SH}$ stretching vibrations in the photogenerated thiol-imino forms of thiourea and thioacetamide were found at 2625 and $2607 \mathrm{~cm}^{-1}$, respectively. ${ }^{1,2}$ Typical intensities of $v(\mathrm{SH})$ bands are so low that these absorptions are

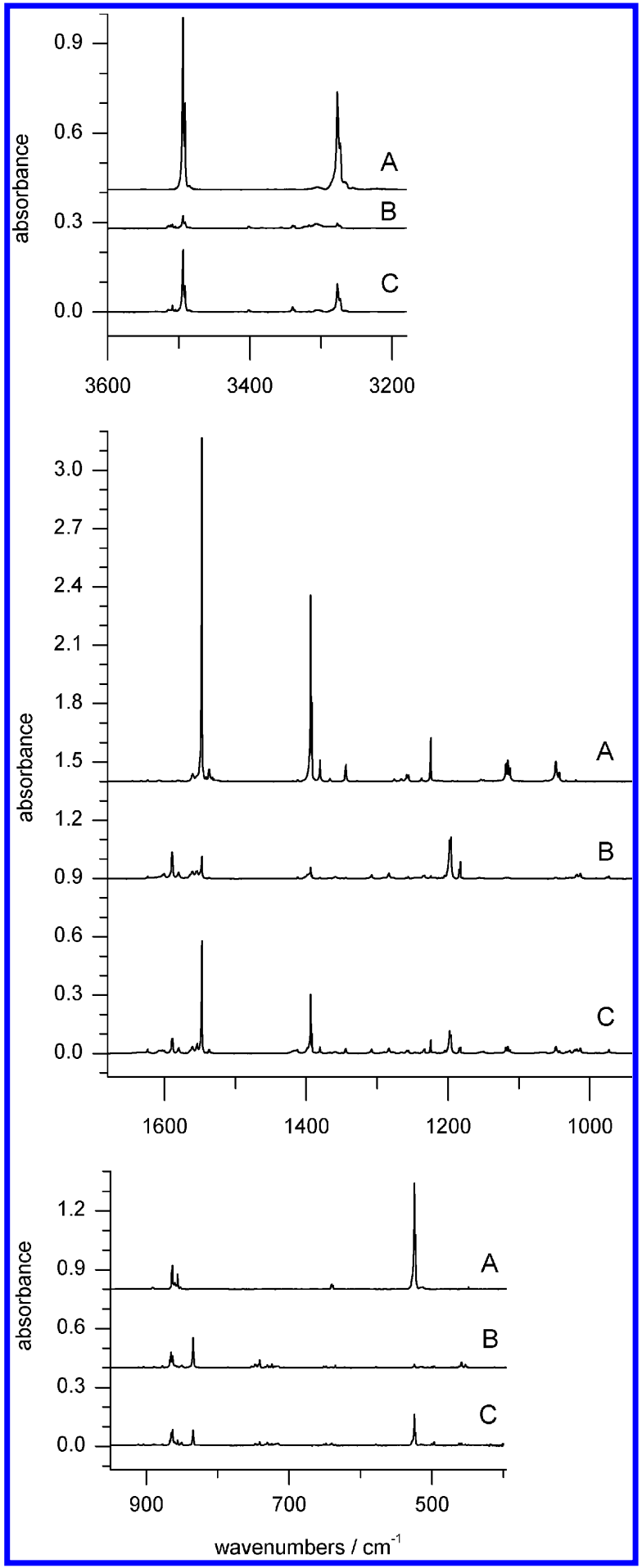

Figure 2. Infrared spectra of dithiooxamide isolated in an Ar matrix: (A) after deposition of the matrix; (B) after $1 \mathrm{~h}$ of $\mathrm{UV}(\lambda>345 \mathrm{~nm})$ irradiation; (C) after subsequent $24 \mathrm{~h}$ of keeping the matrix at $10 \mathrm{~K}$ and in darkness.

hardly detectable. The unusually low frequency and relatively high intensity of the $v(\mathrm{SH})$ band observed in the photoproduct generated from DTO strongly suggest that in this species the $\mathrm{SH}$ groups are involved in an intramolecular hydrogen-bondlike interaction.

Theoretical geometry optimizations revealed that there are 10 stable dithiol-diimino conformers with the sulfur atoms in trans positions with respect to each other and 7 stable conformers with these atoms in the cis orientation (Chart S1 in the Supporting Information). The calculated relative energies of 


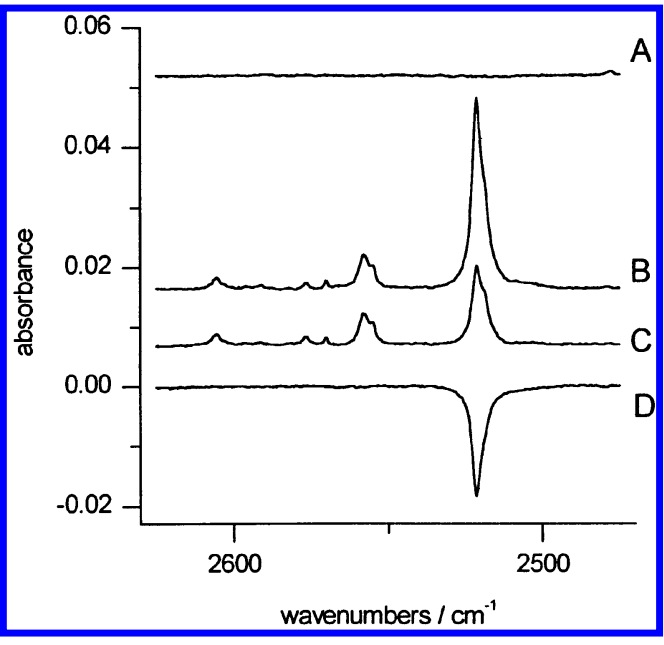

Figure 3. $v(\mathrm{SH})$ range of the IR spectra of dithiooxamide: (A) after deposition of the matrix; (B) after $1 \mathrm{~h}$ of $\mathrm{UV}(\lambda>345 \mathrm{~nm})$ irradiation; (C) after subsequent $24 \mathrm{~h}$ of keeping the matrix at $10 \mathrm{~K}$ and in darkness, (D) spectrum C minus spectrum B.

CHART 3: Conformer III of the Dithiol-Diimino Tautomer of DTO ${ }^{a}$

$$
\text { III }
$$

${ }^{a}$ According to MP2/6-311++G(2d,p) calculations, both $\mathrm{H}-\mathrm{N}=$ $\mathrm{C}-\mathrm{S}-\mathrm{H}$ units are quasi-planar, but they are twisted with respect to each other. The molecule has $C_{2}$ symmetry. The $\mathrm{N}=\mathrm{C}-\mathrm{C}=\mathrm{N}$ dihedral angle is $144.0^{\circ}$.

these conformers are collected in Table S3 (Supporting Information). Among the possible conformers of the dithiol-diimino tautomer of DTO only in form II (presented in Chart 2), both $\mathrm{SH}$ groups are involved in a comparatively strong hydrogenbond-like interaction. In the $C_{2 h}$ structure of form II the $\mathrm{N}(5) \cdots \mathrm{H}(7)-\mathrm{S}$ distance is $2.080 \AA$. The $\mathrm{N} \cdots \mathrm{H}-\mathrm{S}$ intramolecular interaction which closes the five-membered ring is considerably stronger than the analogous interaction in the thiol-imino tautomers of simple monothioamides (where an energetically less favorable four-membered ring is formed). Indeed, the $\mathrm{N} \cdot \cdot \mathrm{H}-\mathrm{S}$ distances in the thiol tautomers of thioacetamide and thioformamide are 2.515 and $2.559 \AA$, respectively. Similarly, the $\mathrm{N}(5) \cdots \mathrm{H}(9)-\mathrm{S}$ distance in conformer III (Chart 3) of the dithiol-diimino tautomer of DTO, where $\mathrm{N} \cdots \mathrm{H}-\mathrm{S}$ interactions closing the four-membered ring are analogous to those in thiolimino tautomers of simple thioamides, was predicted to be 2.522 $\AA$. All distances quoted above concern geometries optimized at the MP2/6-311++G(2d,p) level.

The low frequency and the higher than usual intensity of the $v(\mathrm{SH})$ band in the spectrum of the photoproduced species are well reproduced in the theoretically predicted spectrum for conformer II (see Table 4). The calculated frequency (2562 $\left.\mathrm{cm}^{-1}\right)$ is significantly lower and the calculated intensity (145 $\mathrm{km} \mathrm{mol}^{-1}$ ) is much higher in comparison with the corresponding values calculated for the thiol-imino form of thiourea (2668 $\mathrm{cm}^{-1}$ and $1 \mathrm{~km} \mathrm{~mol}^{-1}$ ) or the thiol-imino form of thioacetamide $\left(2641 \mathrm{~cm}^{-1}\right.$ and $\left.1 \mathrm{~km} \mathrm{~mol}^{-1}\right) .^{1,2}$ Similar values $\left(2639 \mathrm{~cm}^{-1}\right.$ and $1 \mathrm{~km} \mathrm{~mol}^{-1}$ ) were also obtained for conformer III.

The UV-irradiated matrix was subsequently left at $10 \mathrm{~K}$ and in darkness. The infrared beam of the FTIR spectrometer and $\mathrm{HeNe}$ laser beam were blocked during this period. Over $24 \mathrm{~h}$ a
TABLE 4: Experimental Wavenumbers $\left(\tilde{v} / \mathrm{cm}^{-1}\right)$ and Relative Integral Intensities $(I)$ of the Absorption Bands of Photoproducts Generated upon UV $(\lambda>345 \mathrm{~nm})$ Irradiation of Matrix-Isolated Dithiooxamide, Compared with the Wavenumbers $\left(\tilde{v} / \mathbf{c m}^{-1}\right)$, Absolute Intensities $\left[A^{\text {th }} /(\mathbf{k m}\right.$ $\left.\mathrm{mol}^{-1}\right)$ ], and Potential Energy Distribution (PED/\%) Theoretically Calculated for Conformer II of the Dithiol-Diimino Tautomer of the Compound

\begin{tabular}{|c|c|c|c|c|c|}
\hline \multicolumn{3}{|c|}{ experimental, Ar matrix } & \multicolumn{3}{|c|}{ calculated, DFT(B3LYP)/6-31++G(d, p) } \\
\hline$\tilde{v}^{a}$ & $I$ & & $\tilde{v}^{b}$ & $A^{\text {th }}$ & $\mathrm{PED}^{d}$ \\
\hline 3515 & 11 & - & & & \\
\hline 3511 & 11 & & & & \\
\hline 3509 & 9 & $\uparrow$ & & & \\
\hline 3505 & 5 & $\uparrow$ & & & \\
\hline 3401 & 10 & - & & & \\
\hline & & & 3438 & 21 & $v(\mathrm{NH})(98)$ \\
\hline 3356 & 5 & $\downarrow$ & & & \\
\hline 3340 & 12 & $\uparrow$ & & & \\
\hline 3337 & 7 & $\downarrow$ & & & \\
\hline 3307 & 84 & $\downarrow$ & & & \\
\hline 2605 & 3 & - & & & \\
\hline 2577 & 4 & - & & & \\
\hline 2570 & 1 & - & & & \\
\hline 2558 & 11 & - & & & \\
\hline 2521 & 71 & $\downarrow$ & 2562 & 145 & $v(\mathrm{SH})(100)$ \\
\hline 1603 & 18 & - & & & \\
\hline $1601 / 1589$ & 191 & $\downarrow$ & 1627 & 231 & $v(\mathrm{C}=\mathrm{N})(96)$ \\
\hline 1580 & 52 & - & & & \\
\hline 1561 & 76 & - & & & \\
\hline 1556 & 29 & $\downarrow$ & & & \\
\hline 1554 & 43 & $\uparrow$ & & & \\
\hline 1397 & 47 & - & & & \\
\hline 1359 & 12 & - & & & \\
\hline 1308 & 18 & - & & & \\
\hline 1284 & 48 & - & & & \\
\hline 1235 & 12 & - & & & \\
\hline 1233 & 14 & $\uparrow$ & & & \\
\hline $1198 / 1196 / 1184 / 1183$ & 427 & $\downarrow$ & 1211 & 338 & $\beta(\mathrm{NH})(85)$ \\
\hline $1018 / 1013$ & 66 & - & & & \\
\hline 976 & 6 & $\downarrow$ & & & \\
\hline 973 & 8 & $\uparrow$ & & & \\
\hline 911 & 3 & - & & & \\
\hline 904 & 3 & - & & & \\
\hline 877 & 4 & $\downarrow$ & & & \\
\hline $867 / 865$ & 80 & $\downarrow$ & 894 & 111 & $\beta(\mathrm{SH})(80), \beta(\mathrm{NH})(12)$ \\
\hline 850 & 17 & $\uparrow$ & & & \\
\hline 834 & 132 & $\downarrow$ & 828 & 108 & $\tau(\mathrm{NH})$ \\
\hline $747 / 741 / 727 / 724$ & 81 & $\downarrow$ & 740 & 37 & $v(\mathrm{CS})(75), \beta(\mathrm{C}=\mathrm{N})(17)$ \\
\hline 730 & 16 & - & & & \\
\hline 715 & 22 & - & & & \\
\hline 651 & 6 & - & & & \\
\hline 648 & 5 & - & & & \\
\hline 635 & 7 & $\downarrow$ & & & \\
\hline 578 & 3 & - & & & \\
\hline 500 & 6 & - & & & \\
\hline 497 & 7 & $\uparrow$ & & & \\
\hline 462 & 7 & - & & & \\
\hline $458 / 453$ & 33 & $\downarrow$ & 443 & 32 & $\beta(\mathrm{C}=\mathrm{N})(88)$ \\
\hline & & & 384 & 55 & $\tau(\mathrm{SH})(62)$, wag thioamide (36) \\
\hline 365 & 16 & $\downarrow$ & 365 & 11 & wag thioamide (60), $\tau(\mathrm{SH})(36)$ \\
\hline 293 & 16 & & & & \\
\hline 228 & 9 & $\downarrow$ & 247 & 26 & $\beta(\mathrm{CS})(98)$ \\
\hline & & & 68 & 0.4 & twist C $-\mathrm{C}(99)$ \\
\hline
\end{tabular}

${ }^{a}$ Wavenumbers of the strongest bands are italic. ${ }^{b}$ Theoretical wavenumbers were scaled by a factor of $0.98 .{ }^{c}$ Bands of the photoproducts: $\downarrow$, decreasing; $\uparrow$, increasing; - , unchanged during the period when the matrix was kept in darkness and at $10 \mathrm{~K} .{ }^{d}$ PEDs lower than $10 \%$ are not included. Symmetry coordinates used in the normal-mode analysis are given in Table 3 .

systematic recovery of the initial dithione-diamino form $\mathbf{I}$ of DTO was observed (see Figure 2). This process was accompanied by the decrease of a set of bands in the spectrum due to the photoproduct(s). The most intense bands that appeared after UV irradiation belong to this set. These bands, as well as all other bands that were intense enough to allow measurement of the time evolution of their decline, decreased at the same rate. However, not all bands that appeared after UV irradiation 

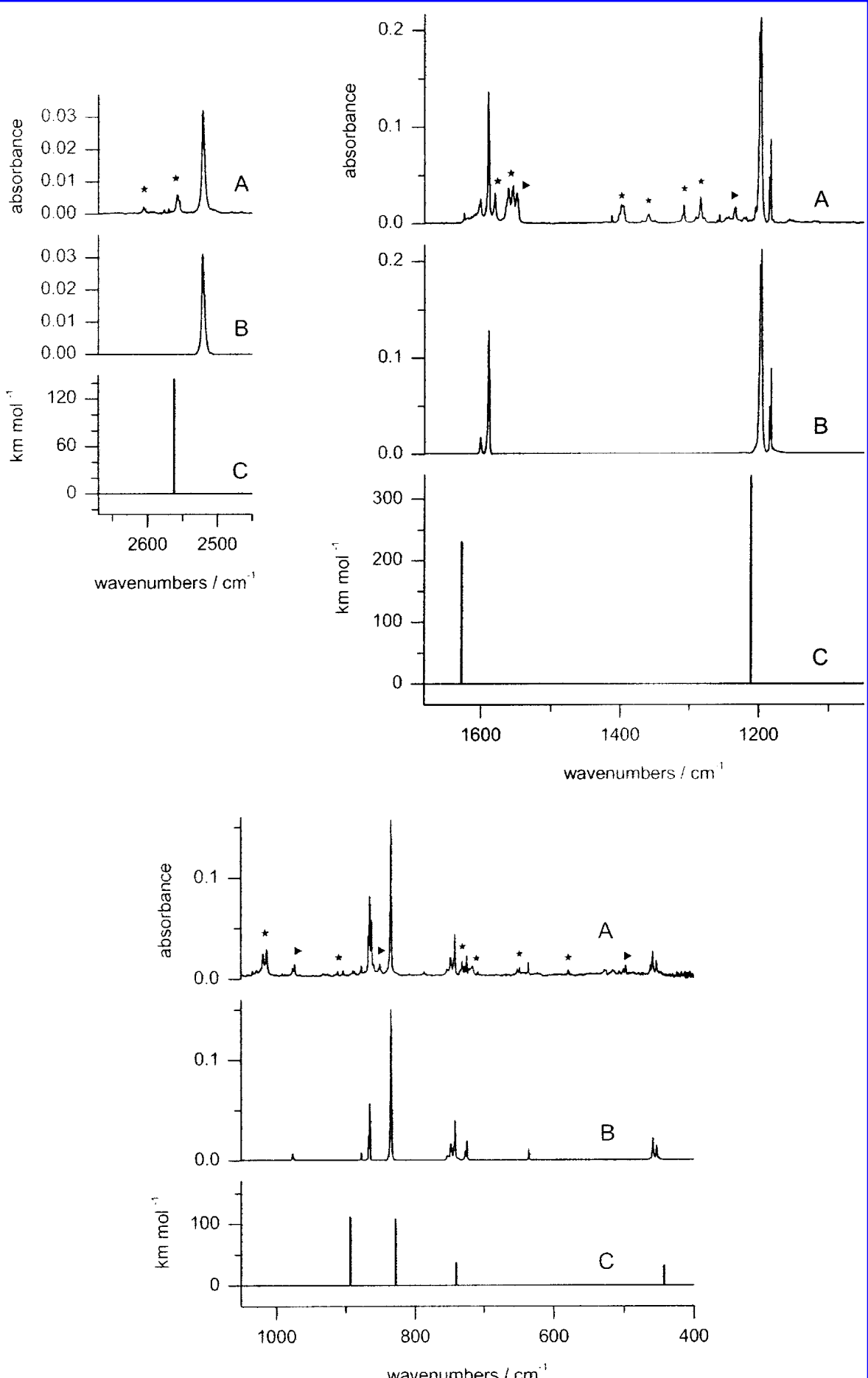

Figure 4. (A) Infrared spectrum of photoproducts generated upon UV $(\lambda>345 \mathrm{~nm})$ irradiation of dithiooxamide isolated in an Ar matrix. Bands of the main photoproduct are not marked (all these bands decay at the same rate during the tunneling back to form $\mathbf{I}$ ). Bands marked with an asterisk do not change their intensities; those marked with a solid arrow grow during this period. (B) Extracted spectrum of the bands due to the main photoproduct. (C) Theoretically predicted spectrum (at the DFT(B3LYP)/6-31++G(d,p) level) for conformer II of the dithiol tautomer of dithiooxamide. Theoretical wavenumbers were scaled by a factor of 0.98 .

decreased during the time when the matrix was kept in darkness. Some of the least intense bands increased in intensity, whereas some others did not change at all (see Table 4, Figure 4, and Figure S1). Among the bands belonging to the last category, those found at 2605, 2577, 2570, and $2558 \mathrm{~cm}^{-1}$ indicate that, alongside the main dithiol-diimino photoproduct with the characteristic $v(\mathrm{SH})$ band at $2521 \mathrm{~cm}^{-1}$, several other dithioldiimino conformers were also photogenerated (see Figure 3 ).

Equal rates of decrease during the period when the matrix was kept in darkness allowed for positive identification of the bands belonging to the spectrum of the main photoproduct. The extracted spectrum of those bands is well reproduced by the calculated spectrum of the dithiol-diimino conformer II. The graphical comparison presented in Figure 4 (see also Table 4) strongly supports the assignment of the main photoproduct to form II.

While the UV-irradiated matrix was kept in darkness, the recovery of the dithione-diamino form of DTO was periodically monitored. After $24 \mathrm{~h}$ the IR bands of the dithione-diamino tautomer regained $32 \%$ of their initial intensities recorded just 


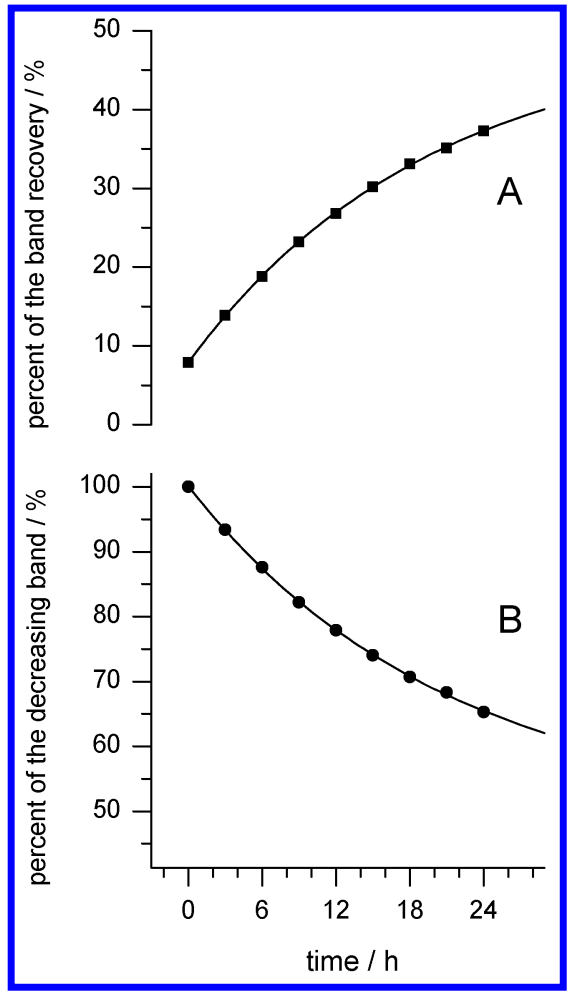

Figure 5. (A) Progress of the recovery of the dithione tautomer I of dithiooxamide measured as the intensity increase of the band at 1547 $\mathrm{cm}^{-1}$. A value of $100 \%$ corresponds to the intensity of the band before UV irradiation. (B) Decrease of the band at $1589 \mathrm{~cm}^{-1}$, from the spectrum of form II, as a function of time. A value of $100 \%$ corresponds to the intensity of the band immediately after irradiation. For both panels, the time scale begins at the moment when the UV irradiation ceased.

after deposition of the matrix. The recovery of the representative band at $1547 \mathrm{~cm}^{-1}$ is presented in Figure 5A as a function of time. The time constant for the dithiol-diimino $\rightarrow$ dithionediamino process, obtained from the fit of the function $y=y_{0}+$ $A\left(1-\mathrm{e}^{-k t}\right)$ to the experimental points shown in Figure 5A, is $18 \mathrm{~h}$. The time evolution of the decreasing bands due to form II, during the period of $24 \mathrm{~h}$ of keeping the matrix in darkness, is presented in Figure 5B. The rate of decrease of these bands is the same as the rate of increase of the bands due to dithionediamino tautomer $\mathbf{I}$. This shows that the major tunneling process II $\rightarrow$ I is not significantly perturbed by any other isomerization occurring in darkness.

\section{Concluding Discussion}

In the present study, two proton-transfer processes leading to transformation between isomers I and II of DTO were observed. One of these processes corresponds to UV-induced double-proton transfer, $\mathbf{I} \rightarrow$ II. Upon electronic excitation two protons are transferred from the nitrogen atoms to the sulfur atoms placed in the $\beta$ positions.

The other process is the ground-state II $\rightarrow$ I tautomerism occurring in the dark. A barrier for transformation of the dithiol-diimino isomer II into the dithione-diamino tautomer I, by concerted movement of two protons in the electronic ground state, was theoretically assessed (at the MP2/6-311++(2d,p) level) using the minimum energy path approach. Those calculations predicted a barrier height of $23 \mathrm{~kJ} \mathrm{~mol}^{-1}$. At cryogenic temperature $(10 \mathrm{~K})$, thermal isomerization over such a barrier is very unlikely. Therefore, the only possible mechanism of the ground-state II $\rightarrow$ I tautomerization is proton

\section{CHART 4: Conformation IV of Dithiooxamide}

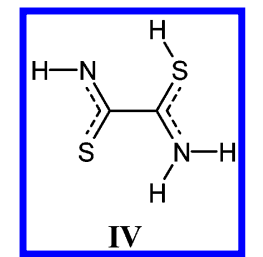

tunneling. ${ }^{19}$ Two routes of such transformation could be considered: (i) stepwise tunneling of one and then of the other proton; (ii) simultaneous movement of both protons.

Stepwise transformation of dithiol-diimino isomer II, first into a thiol-thione isomer, IV (Chart 4), and then, in a second act, into the dithione-diamino form $\mathbf{I}$, does not seem possible. The structure of the transient form IV is not canonical, and there is no minimum on the potential energy surface (PES) corresponding to such a configuration. The energies of the PES points around structure IV are higher by $60-80 \mathrm{~kJ} \mathrm{~mol}^{-1}$ with respect to the dithiol-diimino isomer II (as results from calculations carried out at the MP2/6-311++G(2d,p) level). Hence, the energy conservation law should preclude stepwise tunneling of one proton $(\mathbf{I I} \rightarrow \mathbf{I V})$ and then of the other $(\mathbf{I V} \rightarrow \mathbf{I})$ on the way from dithiol-diimino isomer II to the dithione-diamino tautomer $\mathbf{I}$.

For single-proton-tunneling processes in thiourea and selenourea, ${ }^{1,9}$ the calculated ground-electronic-state barriers (105 $\mathrm{kJ} \mathrm{mol}^{-1}$ for thiourea and $95 \mathrm{~kJ} \mathrm{~mol}^{-1}$ for selenourea) are significantly higher than the barrier for double-proton transfer in DTO. Moreover, in DTO the distance for each of the protons to tunnel during the dithiol-diimino (II) $\rightarrow$ dithione-diamino (I) transformation is only $1.1 \AA$, whereas for thiourea and selenourea the corresponding values are 2.2 and $2.3 \AA$, respectively. Although these two factors (barrier height and tunneling distance) are much more favorable in the case of DTO, the time constant $(18 \mathrm{~h})$ of the tunneling process is of the same order as those for thiourea and selenourea (52 and $16 \mathrm{~h}$, respectively). This can be rationalized by taking into account the fact that the necessity of simultaneous crossing of the barrier by two protons in a single act must considerably lower the probability of such an event.

Proton-tunneling processes were previously observed also for other molecules (such as formic acid, ${ }^{20}$ 2,5-dichloro-3,6dihydroxy-1,4-benzoquinone, ${ }^{21}$ and tetrachlorohydroquinone ${ }^{22}$ ) isolated in low-temperature matrixes. The calculated energy barriers for these processes were 33, 33, and $19 \mathrm{~kJ} \mathrm{~mol}^{-1}$, respectively. Although these values are quite similar to that calculated for DTO, the time constants of the proton-tunneling processes in formic acid and in the hydroquinones were dramatically shorter (varied from several minutes to less than $1 \mathrm{~min}$ ). The drastic difference in the tunneling rates must be a consequence of the number of protons (two for DTO and one for the other compounds) involved in the process.

Concerted tunneling processes involving more than one proton are not unusual. Most popular are inversions of amino groups and rotations of methyl groups. ${ }^{23-25}$ However, these are usually very quick occurrences in a symmetric or periodic potential. Apart from some analogies with these processes, the very slow dithiol-diimino $\rightarrow$ dithione-diamino double-proton tunneling in isolated molecules of DTO is quite unique. As far as we are aware, the present observation of such a type of process is unprecedented.

Acknowledgment. This work was partially supported by the Portuguese Fundação para a Ciência e a Tecnologia (Research Project POCTI/QUI/43366/2001) and FEDER. 
Supporting Information Available: Full set of symmetry coordinates used in the normal-mode analysis for the dithionediamino tautomer I (Table S1), frequencies and forms of the normal modes calculated for this isomer (Table S2), structures of the stable conformers of the dithiol-diimino tautomer of DTO (Chart S1, Table S3), and fragments of the IR spectrum of DTO illustrating different patterns of behavior during the period of keeping the matrix at $10 \mathrm{~K}$ and in darkness (Figure $\mathrm{S} 1)$. This material is available free of charge via the Internet at http://pubs.acs.org.

\section{References and Notes}

(1) Rostkowska, H.; Lapinski, L.; Khvorostov A.; Nowak, M. J. J. Phvs. Chem. A 2003, 107, 6373.

(2) Lapinski, L.; Rostkowska, H.; Khvorostov A.; Nowak, M. J. Phvs. Chem. Chem. Phvs. 2003, 5, 1524.

(3) Nowak, M. J.; Lapinski, L.; Rostkowska, H.; Les, A.; Adamowicz, L. J. Phys. Chem. 1990, 94, 7406.

(4) Prusinowska, D.; Lapinski, L.; Nowak M. J.; Adamowicz, L. Spectrochim. Acta 1995, 51A, 1809.

(5) Nowak, M. J.; Lapinski, L.; Fulara, J.; Les, A.; Adamowicz, L. J. Phys. Chem. 1991, 95, 2404.

(6) Lapinski, L.; Nowak, M. J.; Kolos, R.; Kwiatkowski, J. S.; Leszczynski, J. Spectrochim. Acta, A 1998, 54, 685.

(7) Rostkowska, H.; Lapinski, L.; Nowak, M. J. J. Phvs. Chem. A 2003, 107, 804.

(8) Wheatley, P. J. J. Chem. Soc. 1965, 1.

(9) Rostkowska, H.; Lapinski, L.; Khvorostov, A.; Nowak, M. J. Chem. Phvs. 2004, 298, 223.

(10) Becke, A. D. Phvs. Rev. A 1988, 38, 3098.
(11) Lee, C. T.; Yang, W. T.; Parr, R. G. Phvs. Rev. B 1988, 37,

(12) Vosko, S. H.; Wilk, L.; Nusair, M. Can. J. Phvs. 1980, 58, 1200.

(13) Hariharan, P. C.; Pople, J. A. Mol. Phys. 1974, 27, 209.

(14) Keresztury, G.; Jalsovszky, G. J. Mol. Struct. 1971, 10, 304.

(15) Møller, C.; Plesset, M. S. Phys. Rev. 1934, 46, 618.

(16) Head-Gordon, M.; Pople, J. A.; Frisch, M. J. Chem. Phvs. Lett. 1988, 153, 1988

(17) Frisch, M. J.; Trucks, G. W.; Schlegel, H. B.; Scuseria, G. E.; Robb, M. A.; Cheeseman, J. R.; Zakrzewski, V. G.; Montgomery, J. A., Jr.; Stratmann, R. E.; Burant, J. C.; Dapprich, S.; Millam, J. M.; Daniels, A. D.; Kudin, K. N.; Strain, M. C.; Farkas, O.; Tomasi, J.; Barone, V.; Cossi, M.: Cammi, R.; Mennucci, B.; Pomelli, C.; Adamo, C.; Clifford, S.; Ochterski, J.; Petersson, G. A.; Ayala, P. Y.; Cui, Q.; Morokuma, K.; Malick, D. K.; Rabuck, A. D.; Raghavachari, K.; Foresman, J. B.; Cioslowski, J.; Ortiz, J. V.; Stefanov, B. B.; Liu, G.; Liashenko, A.; Piskorz, P.; Komaromi, I.; Gomperts, R.; Martin, R. L.; Fox, D. J.; Keith, T.; Al-Laham, M. A.; Peng, C. Y.; Nanayakkara, A.; Gonzalez, C.; Challacombe, M.; Gill, P. M. W.; Johnson, B. G.; Chen, W.; Wong, M. W.; Andres, J. L.; Head-Gordon, M.; Replogle, E. S.; Pople, J. A. Gaussian 98, Revision A.7.; Gaussian, Inc.: Pittsburgh, PA, 1998.

(18) Dapprich, S.; Frenking, G. Chem. Phys. Lett. 1993, 205, 337.

(19) Trommsdorff, H. P. Adv. Photochem. 1998, 24, 147.

(20) Pettersson, M.; Maçôas, E. M. S.; Khriachtchev, L.; Lundell, J.; Fausto, R.; Räsänen, M. J. Chem. Phvs. 2002, 117, 9095.

(21) Akai, N.; Kudoh, S.; Takayanagi, M.; Nakata, M. J. Phvs. Chem. A 2002, 106, 11029.

(22) Akai, N.; Kudoh, S.; Nakata, M. J. Phvs. Chem. A 2003, 107, 3655.

(23) Lin, C. C.; Swalen, J. D. Rev. Mod. Phvs. 1959, 31, 841

(24) Owen, N. L. Studies of Internal Rotation by Microwave Spectroscopy. In Internal Rotation in Molecules; Orville-Thomas, W. J., Ed.; John Wiley \& Sons: London, New York, Sydney, Toronto, 1974; Chapter 6.

(25) Howard, D. L.; Robinson, T. W.; Fraser, A. E.; Kjaergaard, H. G. Phvs. Chem. Chem. Phvs. 2004, 6, 719. 